\title{
Endovascular Intervention for Repositioning the Distal Catheter of Ventriculo-Atrial Shunt
}

\author{
Botao Xu, MD, Silky Chotai, MD, Kaijun Yang, MD, Wenfeng Feng, MD, Guozhong Zhang, MD, \\ Mingzhou Li, MD, Songtao Qi, MD, PhD
}

Displacement of distal ventriculo-atrial (VA) shunt is not uncommon. However, misplacement of the distal catheter of VA shunt in the internal jugular vein is a possibility, especially when conducted without intraoperative monitoring. We describe a patient in whom a VA shunt was performed due to failure of ventriculo-peritoneal shunt and the distal catheter of the shunt was found to be misplaced in the left internal jugular vein. Endovascular intervention via femoral vein was used to retrieve the distal catheter.

Key Words : Ventriculoatrial shunt; Endovascular; Distal catheter; Hydrocephalus; Intraoperative monitoring

Ventriculoperitoneal (VP) shunt is the preferred modality for the diversion of the cerebrospinal fluid (CSF) in the treatment of hydrocephalus. However, shunting of fluid into atrial cavity should be sought for if the VP shunt fails due to intraabdominal adhesion, local infections and scarring from the previous surgery, blockage at the peritoneal or ventricular end, shunt infection, intraabdominal pseudocyst formation, fracture, dislodgement and migration of the tubing, and bowel perforation [1]. Appropriate placement of catheter is very important to prevent the serious complications associated with ventriculoatrial (VA) shunt [2]. With complex venous anatomy in the neck, more so of the left side, catheter tip could be

\footnotetext{
All authors: Department of Neurosurgery, Southern Medical University, Nanfang Hospital, Guangzhou, China

Received April 12, 2012;

accepted after revision June 29, 2012.

Correspondence to: Songtao Qi, MD, PhD, Department of Neurosurgery, Nanfang Hospital, Southern Medical University, Guangzhou, Guangdong, 510515, China.

E-mail: qisongtao1@hotmail.com

This is an Open Access article distributed under the terms of the Creative Commons Attribution Non-Commercial License (http://creativecommons.org/licenses/by-nc/3.0) which permits unrestricted non-commercial use, distribution, and reproduction in any medium, provided the original work is properly cited.
}

misplaced. We present a case that the misplaced distal tip of VA shunt was successfully managed with endovascular intervention via femoral vein.

\section{CASE REPORT}

A 33-year-old male was referred to our hospital with infection of the distal end of the catheter 20 days after the ventriculoperitoneal shunt. He has a past history of head injury in a road traffic accident six months ago. He presented with loss of consciousness and right temporal lobe uncal herniation. CT scan revealed right temporal lobe contusion with hematoma. Emergency craniotomy was performed for drainage of hematoma with decompressive craniectomy. Postoperative period was marked by lost consciousness. A left ventriculoperitoneal shunt was performed for traumatic hydrocephalus. Cranioplasty was accomplished after three months of decompressive craniectomy. On postoperative day 15 , the patient experienced fever with temperature of $39^{\circ} \mathrm{C}$ with increased intracranial tension. CT scan revealed recurrence of hydrocephalus. Blockage of peritoneal end of catheter was confirmed followed by replacement. Catheter tip was positive for staphylococcus epidermis infection. Peritoneal fluid did not show any infection. He was 
started on antibiotics. On postoperative day 20, oozing of pus from the abdominal incision site was noted, with wound gapping. Immediate debridement of the wound was done followed by delayed suture. The patient was then referred to our hospital. On admission

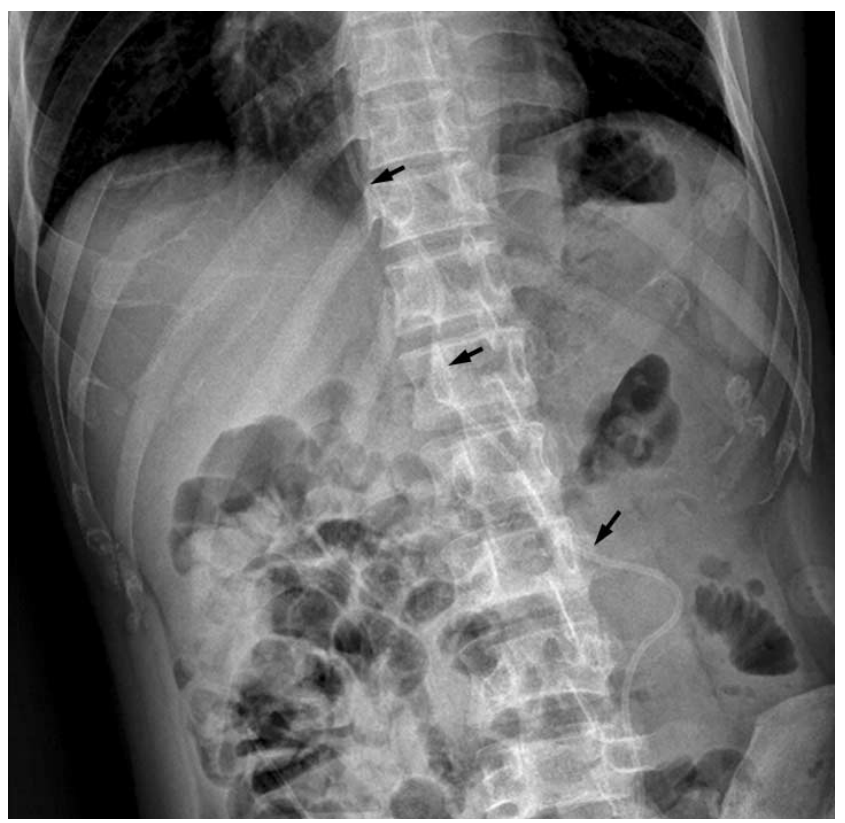

Fig. 1. Abdominal X-ray demonstrating the peritoneal end of the ventriculoperitoneal shunt catheter (arrows). he was unconscious with purulent fluid oozing out from the abdominal incision. Abdominal X-ray showed peritoneal end of the shunt was located accurately (Fig. 1).

Further replacement of peritoneal shunt might increase the chances of failure owing to the recurrent abdominal infection and inflammation. VA shunt was then considered. We decided to conserve the ventricular shunt and the pressure adjusted pump, with removal of the peritoneal shunt from the pump. A new distal catheter was connected to the pump. Under general anesthesia, the incision was made across the anterior border of the left sternomastoid muscle and the left common facial vein was identified. A small opening was made into the common facial vein and the shunt was then expected to pass down to the left jugular vein, subclavian vein and then to the right atrium. The passage was smooth till $6 \mathrm{~cm}$ of shunt remained out, then we encountered a resistance, which was subdued due to continued movement. After the complete insertion of the shunt catheter we severed the left common facial vein, ligated the distal end of the vein and the proximal end was ligated to the catheter. The chest $\mathrm{X}$-ray done in the recovery room did not reveal the shunt at the T6 level (Fig. 2A). An X-ray of neck demonstrated that the distal catheter tangled back in the
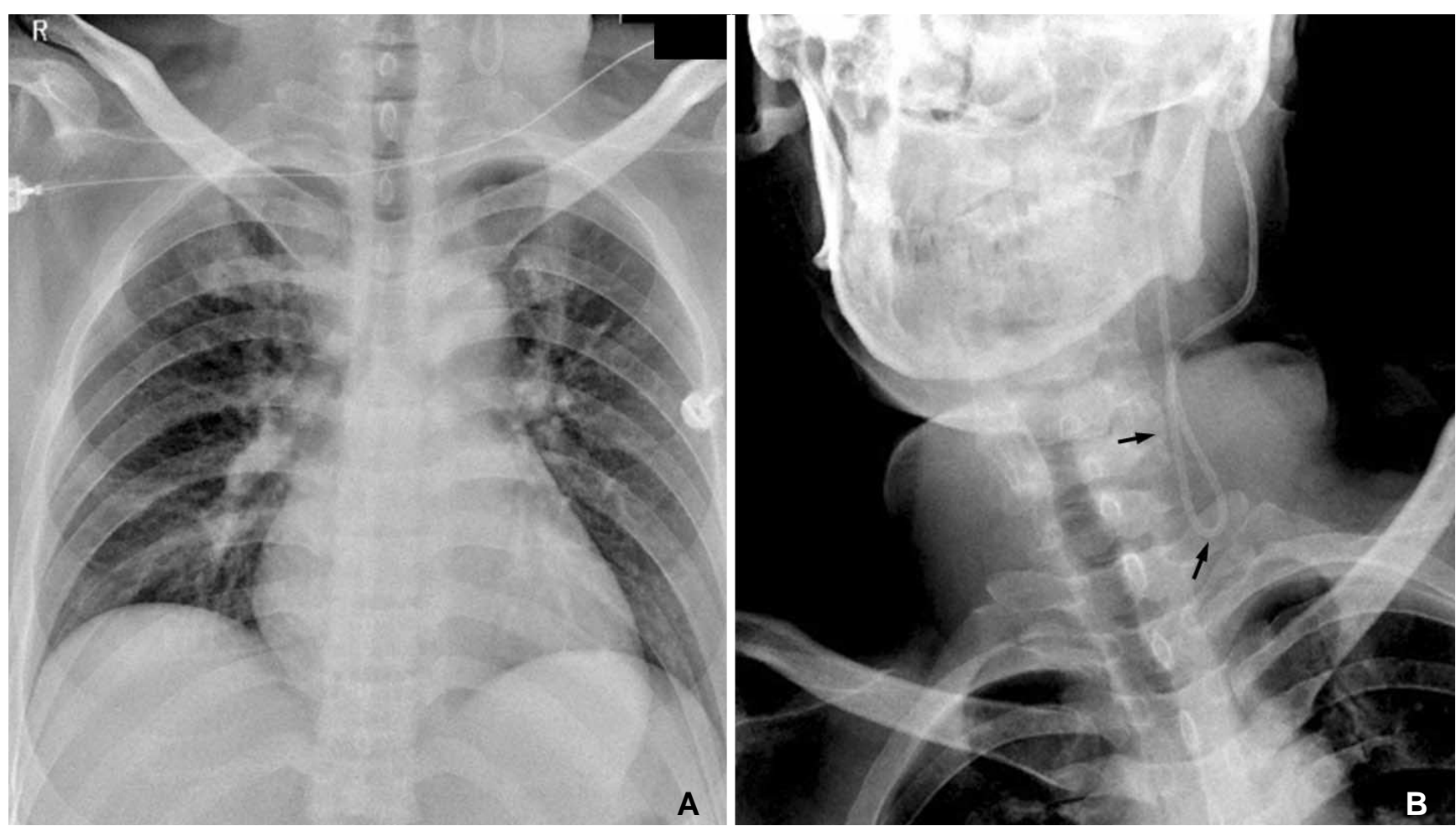

Fig. 2. A. Chest $X$-ray post ventriculoatrial shunt procedure showing the absence of catheter in the T6 vertebral level.

B. X-ray neck showing the distal catheter back in the jugular vein before entry into the subclavian vein (arrows). 


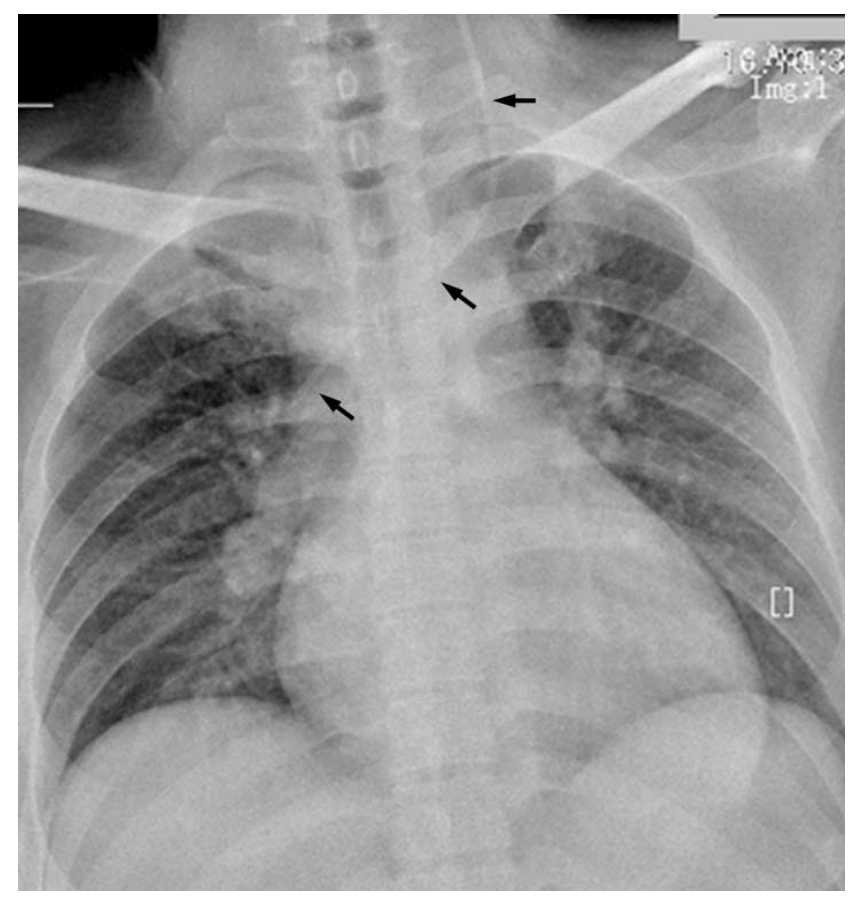

Fig. 3. Chest $X$-ray after endovascular retrieval demonstrating the catheter positioned at T6/ atrial level (arrows).

jugular vein before the entry into subclavian vein (Fig. 2B). Endovascular intervention via femoral vein intervention was then planned to draw the distal shunt into right atrium. Under local anesthesia, a $6 \mathrm{~F}$ sheath was inserted into the right femoral vein by Seldinger method. A 5F guiding catheter was then advanced into the left subclavian vein, followed by imaging to determine the location of the shunt. A $4 \mathrm{~mm}$ Gooseneck loop snare was promoted through the left jugular vein to capture and ligate the tip of the shunt catheter. Finally, the shunt end was dragged into the right atrium smoothly. Post procedure chest X-ray confirmed the accurate position of the distal catheter of the shunt in right atrium (Fig. 3). Following endovascular re-positioning, the shunt function was optimal.

\section{DISCUSSION}

VA shunt offers a promising alternative in event of failure of VP shunt. While conducting the VA shunt, the goal is to position the tip of the distal catheter midway between the entrance into right atrium and the tricuspid valve. Accurate placement and the confirmation of such a placement are technically difficult. This is particularly true when the venous anatomy and the appropriate entry point are not identified intraoperatively. Intraoperative monitoring for the placement of the distal catheter tip has been described using electro- cardiographic waveform changes, vascular pressure changes monitoring, precardial echocardiograph monitoring, transesophageal echocardiography monitoring, ultrasonic guided percutaneous insertion, and fluoroscopy guided catheter insertion [2-5]. A total of eleven VA shunt, has been performed in our hospital without any intraoperative monitoring and the optimal placement of catheter has been achieved in all of the cases. However, those eleven cases were of right VA shunt. In the present case of left VA shunt, the catheter migrated in the left jugular vein towards the jugular foramen, which could be attributed to the complex anatomy of neck veins on left side. As well comprehended, on the left side the venous anatomy is more complex, which could preclude the optimal placement of the distal catheter. The fluoroscopic guided placement of distal catheter end is therefore preferred. However, on occasions when fluoroscopy cannot be availed to guide the catheter such a complication might be encountered. Further, direct venography, ultrasound, and magnetic resonance venography done preoperatively may prove useful to locate the venous anatomy. In the present case, due the technical failure in the imaging machine the intraoperative imaging was not available.

We had two options to deal with the malpositoned distal catheter, one was to surgically retrieve the catheter and repositioning and the second was to retrieve the distal catheter nonsurgically. Nonsurgical retrieval of a broken guide wire from the circulatory system was reported using a bronchoscope forceps as early as 1964 [6]. Since then a variety of commercially available devices such as loop snare, grasping forceps, basket, deflecting wires and balloon catheter has been used for retrieval of intravascular foreign bodies [7]. The retrieval of the distal end of the VA shunt by percutaneous cardiac catheterization via femoral vein has been described in the literature $[8,9]$. Further, the endovascular placement of the atrial end of the catheter via the femoral vein has been described [10]. Based on this evidence, we attempted the interventional endovascular retrieval of the distal catheter.

Misplacement of distal catheter of the VA shunt is the possibility in view of complex left sided neck venous anatomy, when the intraoperative venography, fluoroscopy, and ultrasonography aid are not available. The retrieval of the malpositoned distal catheter can be achieved successfully by interventional endovascular technique via femoral vein. 


\section{Botao Xu, et al.}

\section{References}

1. Weprin BE, Swift DM. Complications of ventricular shunts. Techniques in Neurosurgery 2002;7:224-242

2. Metellus P, Hsu W, Kharkar S, Kapoor S, Scott W, Rigamonti D. Accuracy of percutaneous placement of a ventriculoatrial shunt under ultrasonography guidance: a retrospective study at a single institution. J Neurosurg 2009;110:867-870

3. Cantu RC, Mark VH, Austen WG. Accurate placement of the distal end of a ventriculo-atrial shunt catheter using vascular pressure changes. Technical note. J Neurosurg 1967;27:584-586

4. Gonzalez LF, Kim L, Rekate HL, McDougall CG, Albuquerque FC. Endovascular placement of a ventriculoatrial shunt. Technical note. J Neurosurg 2007;106(Suppl 4):319-321

5. Machinis TG, Fountas KN, Hudson J, Robinson JS, Troup EC. Accurate placement of the distal end of a ventriculoatrial shunt with the aid of real-time transesophageal echocardiography. Technical note. J Neurosurg 2006;105:153-156
6. Thomas J, Sinclair-Smith B, Bloomfield D, Davachi A. Nonsurgical retrieval of a broken segment of steel spring guide from the right atrium and inferior vena cava. Circulation 1964;30:106108

7. Koseoglu K, Parildar M, Oran I, Memis A. Retrieval of intravascular foreign bodies with goose neck snare. Eur J Radiol 2004;49: 281-285

8. Ekong CE, Gabriel YH, Lopez JF. Percutaneous transfemoral retrieval of the "runaway" ventriculoatrial shunt. Can J Surg 1979; 22:456-457

9. Tatsumi T, Howland WJ. Retrieval of a ventriculoatrial shunt catheter from the heart by a venous catheterization technique. Technical note. J Neurosurg 1970;32:593-596

10. Tubbs RS, Barnhart D, Acakpo-Satchivi L. Transfemoral vein placement of a ventriculoatrial shunt. Technical note. J Neurosurg 2007;106(Suppl 1):68-69 